\title{
Bucak Sözcüğünün Etimolojisi Üzerine
}

\section{Öznur DURGUN*}

Öz

Türkiye Türkçesinde 'kenar, köşe, yer' manalarıyla kullanılan, tarihî ve çağdaş Türk dillerinde buçgak $\sim$ buççak $\sim$ buçhak $\sim$ buçhah $\sim$ burçak $\sim$ bucek vb. şekillerde görülen bucak sözcüğü, çoğu araştırmacı tarafından bıç-/biç- 'kesmek' fiiliyle irtibatlandırılmıştır. Sözcüğün, semantik ve morfolojik bakımlardan hayli problemli olan ve ilk defa Vámbéry (1878) tarafından önerilen bıç-/biç- fiiliyle münasebetinin kurulamaması, ayrıca bazı çağdaş Türk dillerinde sözcüğün kökü olduğunu düşündüğümüz, bu zamana kadar gözden kaçan ismin yalın hâlde yaşamaya devam etmesi, bu çalışmanın kaleme alınmasına zemin oluşturmuştur. Çalışmada öncelikle sözcügün tarihî ve çağdaş Türk dillerinde hangi biçimlerde kullanıldığ gösterilmiş, sözcüğe dair yapılan etimolojiler kronolojik olarak incelenmiştir. Sunduğumuz etimolojik izahla, araştırmacıların şimdiye kadar fiil kökünden geldiğini düşündükleri, yalnızca Brockelmann'ın (1954) isim kökünden gelebileceğini söylemekle birlikte etimolojisinin muallak olduğunu belirttiği bucak sözcügünün sanılanın aksine aslında bir isim kökünden türediği, çağdaş Türk dillerindeki veriler üzerinden ortaya konmuş; varyantları, isim kökünün /r/ fonemi bulundurup bulundurmaması kıstas alınarak üç morfolojik gelişim üzerinden temellendirilmiştir.

Anahtar Kelimeler: bucak, etimoloji/kökenbilgisi, biçimbilgisi, Çağdaş Türk dilleri

\footnotetext{
* Arş. Gör., İstanbul Medeniyet Üniversitesi, Edebiyat Fakültesi, Türk Dili ve Edebiyatı Bölümü, Türkiye. Eposta: oznur.durgun@medeniyet.edu.tr https://orcid.org/0000-0001-5574-0987

Bu çalışmanın hazırlanması sürecindeki yardımlarından ötürü kıymetli Hocam Dr. Hakan AYDEMİR'e müteşekkirim.
} 


\title{
On the Etymology of bucak
}

\begin{abstract}
The word bucak has been used with the meanings of 'edge, corner, side, place' in Turkish and appears in

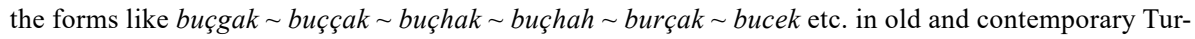
kic languages. Until now, bucak has been associated with blç-/biç- 'cut' verb by many researchers since it was first suggested by Vámbéry (1878). However, this association seems very problematic semantically and morphologically. Moreover, in some contemporary Turkic languages, the stem of the word continues to live in absolute form which escapes the attention of many researchers and these two facts form a basis for this study. First of all, this study tries to show how the word bucak has been used in old and contemporary Turkic languages and then it chronologically examines the etymological inquires made about it. With the etymological exposition, this article propounds that the word bucak actually derives from a noun stem in contrast to the assertion of researchers who have considered bucak as a word deriving from verb stem, apart form Brockelmann (1954) who suggested that it might come from noun stem but its etymology is undecided. The argument has been revealed from data in contemporary Turkic languages, its variants have been grounded on the basis of three morphological developments with regard to the criterion whether noun stem has $/ \mathrm{r} /$ phoneme or not.
\end{abstract}

Keywords: bucak, etymology, morphology, contemporary Turkic languages 


\section{Extended Summary}

Since it was first suggested by Vámbéry, the word bucak has been associated with the verb stem bıç- 'cut' by many scholars although they could not offer a convincing hypothesis regarding its historical development. This article argues that there is no semantic connection between bucak and the verb stem bıç- 'cut'.

First of all, this study chronologically examines the etymological inquiries made about the word bucak, which has been used with the meanings of 'edge, corner, side, place' in Turkish and appears in the forms such as buçgak buç̧̧ak buçhak $\sim$ burçak etc. in old and contemporary Turkic languages.

It is reasonable to claim that relatively first meaning of the word bucak is 'corner' since it has been employed with this meaning nearly in all Turkic languages. In fact, to denote bucak, there exists the forms like buç and burç in some Turkic languages (Tkm., DS, Kmk., DKırTat., Kırg., Uyg., Özb.) which have escaped the attention up to the present. This provides basis for my assertion that bucak and its other forms have derived from burç and the noun stem $* b \bar{u} c ̧>b u c ̧$ which has evolved out of burç. Considering the fact that in Turkic rather than $/ \mathrm{r} /$ epenthesis, $/ \mathrm{r} /$ deletion has been widely seen from Old Turkic onwards (arslan $>a^{r}$ slan $>$ aslan etc.), the change of the word from burç to buç seems quite possible and reasonable (namely: ${ }^{*} b u r c ̧>{ }^{*} b u^{r} c ̧>{ }^{*} b \bar{u} c ̧>b u c ̧$ ). Although the version * $b \bar{u} c ̧$ with a long vowel does not occur independently, Turkmen $b \bar{u} c a k$ and the word $b \bar{u} c \bar{a} k$ recorded by Clauson from the thirteenth century obviously demonstrate the compensatory lengthening arising out of deletion. To explain the variants of the word in Turkic languages, three morphological developments have been followed on the basis of the criterion whether the noun stem has /r/ phoneme or not: burç+Ak, ${ }^{*} b \bar{u} c ̧+g A k$, ${ }^{*} b \bar{u} c ̧+I-m A k$.

1. burç+Ak: Uzbek burçak, Uyghur burcek ve Yellow Uyghur bürçek datas have been analysed on the basis that $+A k$ suffix has been brought to the noun stem burç. This suffix is commonly used with metaphorical sense in Turkic. Along with its dimunitive function, it makes also nouns 
denoting - as Erdal stated - features of the countryside. Old Turkic yolak $<y o l+a k$ (< yol 'way, road') 'a small track in the desert' and özek < $\ddot{o} z+e k$ (< $\ddot{O} z$ 'valley') 'a little waterway' can be cited as examples taking this suffix.

2. $* b \bar{u} c ̧+g A k$ : Relatively most common form in Turkic languages is $* b \bar{u} c ̧+g A k$. This structure occurs by means of the elision of $/ \mathrm{r} /$ phoneme (burç $>* b u r c ̧>* b \bar{u} c ̧>b u c ̧$ ). By the elision of $/ \mathrm{r} /$ phoneme, the form $* b \bar{u} c ̧$ appears and $+g A k(* b \bar{u} c ̧+g a k)$ suffix is brought to the end of it. This suffix makes adjective in Turkic and has the meaning of "being like the entity in the word stem or resembling it characteristically." In this study, it has been presented that this word, which has been found in the form of buçgak in different historical periods of Turkic, has been used independently as $* b \bar{u} c ̧>b u c ̧$ or has been expanded by the already-mentioned suffix. These processes have been described schematically through examples from contemporary Turkic languages by referring to phonetic and morphological developments phase by phase.

3. $* b \bar{u} c ̧+I-m A k$ : I thought that since there is no $*+m A k$ suffix in Turkic which is added to noun, the forms like poçmak in Tatar, pěśmeh in Chuvash and boçmak in Kazan Tatar came into being in the first step by bringing $+\mathrm{I}$ - suffix, which is added to Turkic noun and "...- as Erdal stated - signifies 'to become what the base nominal denotes'", to the stem buç 'köşe' $(<* b \bar{u} c ̧)$. Thus, the word has acquired the meaning of 'becoming corner' (namely: *būç $+I->* b \bar{u} c ̧ ı-)$.

Consequently, this study propounds that the word bucak actually derives from a noun stem. This point is quite significant regarding the fact that until today the researchers have considered bucak as a word deriving from a verb stem, apart from Brockelmann (1954) who has suggested that bucak might come from a noun stem but its etymology is undecided. Moreover, by using the data from contemporary Turkic languages and grounding the variants morphologically, this article presents that bucak has no semantic association with bıç-/biç- verb or the forms in Tunguz, Korean and Mongol. 


\section{Giriş}

Türkiye Türkçesinde 'kenar, köşe, yer' manalarıyla kullanılan bucak sözcüğü üzerine yapılan etimolojiler, çoğu araştırmacının sözcüğü $b \imath c ̧-~ ' k e s m e k '$ fiil kökünden getirdiğini fakat ekine dair - genelde - net bir fikir beyan etmediğini göstermektedir. Sözcüğün bu fiil köküyle semantik münasebetinin kurulamaması ve bazı çağdaş Türk dillerinde sözcüğün kökü olduğunu düşündüğümüz, bu zamana kadar gözden kaçan ismin yalın hâlde yaşamaya devam etmesi, bu çalışmanın kaleme alınmasına zemin oluşturmuştur. İncelediğimiz bucak sözcüğünü, semantik ve morfolojik bakımlardan oldukça problemli olan ve ilk defa Vámbéry (1878) tarafından önerilen bıç-/biç- fiiline dayandırmak yerine var olan bir isim köküyle ilişkilendirmenin daha makul olacağını düşünüyoruz. Sözcüğün etimolojik izahına geçmeden evvel tarihî ve çağdaş Türk dillerinde hangi biçimlerde bulunduğunu görmek faydalı olacaktır:

bucak: ETü.: buçgaksız (EUyg.), buçgāk (DLT); OTü.: 13. yy. būcāk (EDPT), 14. yy. bucāk bucāg (ÇağSeng.), buçgak (CC); YTü.: BTü. bucak (TTü.), buç (DS), bucag (Az.), bucak (Gag.), burç, būcak (Tkm.), KTü.: poçmak (Tat.), bucak (KrmTat.), boçmak (KazTat.), bucak, buçsız buçsuz (DKırTat.), buçak (Kar.), buçhak, buçhah (KarTro.), buçkak (KarKır.), buçhak (KrçBalk.), burç, buç̧̧ak (Kmk.), burç (Kırg.), buruş (KırgRad.), burış (Kzk.), Bşk. - ; DTü.: buc, bucek, bucik (Uyg.), burcek, bucek, buicek, buicuk (UygJar.), bürçek (SUyg.), burç, burçak (Özb.), KDTü. -1, H. - , S. - , Ç. pěśmeh, pěśek, pěçeh (Çuv.)

Eski Türkçeden itibaren buçgak $\sim$ bucak $\sim$ buççak $\sim$ buçkak $\sim$ burçak vb. şekillerde kullanılan sözcüğün etimolojisine dair ilk görüş Vámbéry’e (1878) aittir. Etimolojilerinin çoğu yanlış olsa da, tarihî değeri dolayısıyla mutlak surette bakılması gereken bu ilk etimolojik sözlükte Vámbéry, biç- kökünden türediğini düşündüğü sözcükler arasında 'uç, açı (bütünden kesilmiş, ayrılmış olan)' manalarında buçmak ve buçkak'ı zikretmiş, Osmanlıcada bucak'ın, zikredilen manala-

1 Kuzeydoğu Türkçesi grubuna giren dillerde 'köşe, kenar, açı' manalarında buluך (Hak., Tof., KarCast., Alt., AltGND.)

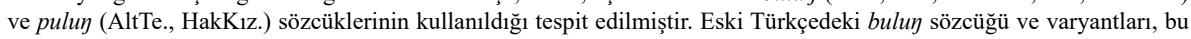
coğrafyada bucak' 1 karşılamak üzere kullanılmaya devam etmektedir. 
rın yanı sıra bir bölgenin ucu olması dolayısıyla Besarabya için de kullanıldığını dile getirmiştir. ${ }^{2}$

Ramstedt (1935), Kalmukça Sözlüğü'nde butsha- '(geri) dönmek' (Ramstedt'te buts $\chi$ a) sözcüğüyle bağlantılı olarak Türkçe buç-kak ve buç-mak 'açı, köşe, dönemeç' sözcüklerini de zikretmiş, fakat bıç- 'kesmek' kökünden gelip gelmediğine dair tereddüdünü soru işareti koyarak temkinli bir şekilde belirtmiştir. $^{3}$

Brockelmann (1954) ise, isim köküne gelerek sıfat yahut küçültme yapt1ğını düşündüğü $+g a k$ ekiyle (Brockelmann'da “ $\gamma a q "=+g a k$ ) türeyen sözcükler arasında buçgak' 1 da zikretmiş, etimolojisinin muallak olduğunu belirtmiştir. ${ }^{4}$

Räsänen (1969) sözcüğün tarihî ve çağdaş Türk dillerindeki biçimlerini vermekle yetinmiş, Moğolca buça 'dönüş', Tunguzca muçū ile arasında bağlantı kurmuştur. $^{5}$

Clauson (1972), bıç- 'bir şeyi kesmek' fiilinden geldiğini düşündüğü DLT bıçgāk sözcügünün Eski Uygurca da dahil olmak üzere bazı dillerde çok erken dönemde labial asimilasyon sonucu $b u c ̧ g \bar{a} k$ şekline dönüştüğünü belirtmiş, ekine dair bir açıklamada bulunmamıştır (yani: $b \iota c ̧ g \bar{a} k>b u c ̧ g \bar{a} k){ }^{6}$

Sevortyan (1978) ise bucak'ın, bıç- fiil kökünden türediği konusunda Clauson ve Zajaczkowski ${ }^{7}$ ile hemfikirdir. Fakat /u/'lu biçimlerin /b/'nin yuvarlaklaştırıcı etkisiyle bıç-'tan açıklanabileceğini, dolayısıyla buçak vb. biçimlerindeki ‘köşe' manasının ikincil olduğunu, yani sonradan ortaya çıktığını düşünmektedir. Sevortyan bu görüşünü desteklemek için Anadolu ağızlarından DS biça 'çatal', DS biçik 'iki derenin birleştiği yer; kesik, biçilmiş vs.' ve DS bıçık 'bucak' sözcüklerini örnek olarak göstermiştir. ${ }^{8}$

Erdal (1991), sözcüğün "muhtemelen” bıç- kökünden -gAk morfemiyle oluştuğunu belirtmiş ve ilk hecedeki ünlünün /b/ fonemi dolayısıyla yuvarlak- 
laştığını Uygurcadaki buluysuz buçgaksız ikilemesiyle örneklendirmiştir (yani: bıç-gAk> *bıçgak $>$ buçgak). ${ }^{9}$

Tietze (2002), Clauson’un görüşüne değinerek sözcüğün bıç- 'kesmek' fiilinden yer ismi yaptığını düşündüğü “- $a k$ eki” ile türediğini söyler. Tietze, " $B u$ $c a k$ ” madde başında ise sözcüğün, Besarabya bölgesinin adı olduğunu ve bölgenin Bizans Yunancasındaki adının 'köşe' manasında Ónglos olduğunu belirtmiştir. ${ }^{10}$

Starostin, Dybo ve Mudrak, müşterek çalışmaları An Etymological Dictionary of Altaic Languages'te (Altay Dilleri'nin Etimolojik Sözlüğü = EDAL 2003) Proto Türkçede *būç-gak, *būç-mak olarak uzun ünlülü tasarladıkları ve Türk dillerindeki farklı biçimlerine yer verdikleri sözcüğü 'köşe, uç, son, bitiş’ manalarındaki Tunguzca *muç-, Korece *mằçh- fiilleriyle ilişkilendirmiş, semantik ve fonetik bakımdan - ünlü uzunluğu ve niteliği - farklı olmaları dolayısıyla *bıç- 'kesmek' kökünden türemediğini ileri sürmüşlerdir. ${ }^{11}$ Sözcüğün hangi ekten türediğine dair bir görüş belirtmeseler de köküne dair ihtiyatlı tutumları dikkat çekmektedir.

Gülensoy (2007) sözcüğü *būç-ga-k şeklinde tahlil etmiş, Moğolca buça$g a$ - 'geri çevirmek, geri göndermek' < *buça- 'geri döndürmek' fiiliyle irtibatlandırmıştır (yani: buçgak $<* b \bar{u} c ̧ g a k<* b \bar{u} c ̧-g a-k<* b \bar{u} c ̧ g a-=$ Mo. buçaga-). ${ }^{12}$

Nişanyan (2009) ise etimoloji sözlüğünde bucak sözcüğünün Eski Türkçe $b \iota c ̧$ - 'kesmek' fiilinden “ $+(g) A k$ ” ekiyle türetildiğini ve buçgak 'kesim, kesit' sözcüğünden evrildiğini belirtmiştir. Ünlü yuvarlaklaşması Nişanyan’a göre ön sesteki /b/ etkisiyledir. ${ }^{13}$

“bucak” sözcüğünün köküne ve etimolojisine dair görüşleri şu şekilde özetlemek mümkündür:

1. < bıç-/biç- + ? : Vámbéry (1878), Clauson (1972), Sevortyan (1978)

2. < bıç-/biç-gAk: (< bıç-gAk?) Ramstedt (1935), Erdal (1991), (< bıçak) Tietze (2002), (< bıç-(g)Ak) Nişanyan (2009)

\section{3. *buç+gak: Brockelmann (1954)}

9 Erdal 1991: 395.

10 Tietze 2002, C I: 387; krş. Karatay 2014.

11 EDAL 2003: 938.

12 Gülensoy 2007: 175.

13 Nişanyan 2009: 81. Sözlüğünün ilk baskısında Nişanyan, Eski Türkçede bıçgak olarak görüldüğünü belirttiği sözcüğün biç- fiil kökünden geldiğini söylemiş, yapısına dair herhangi bir açıklamada bulunmamıştır. (2002: 76) 
4. *būç- + ?: (= Tung. *muç-, Kor. *mằçh-) EDAL (2003)

5. *būçga-k: Gülensoy (2007)

Yukarıdakilerden anlaşılacağı üzere sözcüğün kökünün bir fiil olduğu görüşü - ihtiyatlı davrananlar olmakla birlikte (bk. Ramstedt, EDAL) - araştırmac1lar arasında genel kabul görmüştür. Brockelmann, etimolojisinin her ne kadar açık olmadığını belirtse de buçgak sözcügünün isme gelen +gak ekinden türediğini düşündüğü ve etimolojik izahı diğer araştırmacılardan farklı - fakat görece doğru - olduğu için ayrı bir yere konmalıdır.

Neredeyse tüm Türk dillerinde 'köşe' anlamında kullanılan, dolayısıyla görece birincil anlamının 'köşe' olduğunu düşündüğümüz bucak sözcüğünü karş1lamak üzere bazı Türk dillerinde (Tkm., DS, Kmk., DKırTat., Kırg., Uyg., Özb.) bugüne kadar gözlerden kaçan buç ve burç biçimlerinin bulunması, sözcüğün kökünü çok da uzaklarda aramamamız gerektiğini gösteriyor. Kanaatimizce bucak sözcüğü ve diğer biçimleri, burç ve ondan gelişen *būç > buç isim kökünden türemişlerdir. Türkçede/r/türemesinin aksine/r/düşmesi hadisesinin Eski Türkçe'den itibaren yaygın olarak görülmesi (arslan $>a^{r}$ slan $>$ aslan vs.), burç'tan buç olmasını gayet mümkün ve makul kılmaktadır (yani: ${ }^{*} b u r c ̧>* b u^{r} \zeta{ }^{*} b \bar{u} c ̧>b u c ̧$ ). Müstakil olarak uzun ünlülü *būç biçimine rastlanmasa da Clauson'un 13. yüzyıl için kaydettiği $b \bar{u} c \bar{a} k^{14}$ ve Türkmence $b \bar{u} c a k^{15}$ sözcükleri, fonem düşmesi sonucu ortaya çıan ve fonetikte compensatory lengthening olarak bilinen telafi uzamasını açık bir şekilde göstermektedir. Fonem düşmesiyle görülen bu talî uzunluk hadisesine örnek olarak DLT'deki tōz 'toz' sözcüğü verilebilir. Moğolcadan alın-

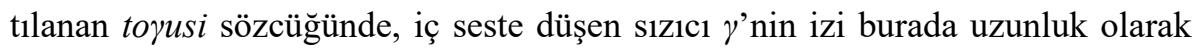

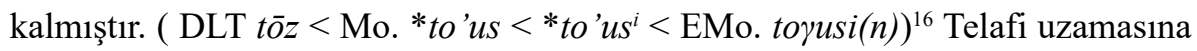
ilişkin benzer örnekler, eski ve yeni Türk dillerinden bolca gösterilebilir.

Bu bağlamda Sevortyan'ın, etimolojisini desteklemek üzere verdiği sözcüklerin (yani: DS biça 'çatal', DS biçik 'iki derenin birleştiği yer; kesik, biçilmiş vs.; bucak' ve DS bıçı 'bucak') semantik ve morfolojik bakımdan farklı yapılar olduğunu özellikle belirtmemiz gerekir (nitekim: DS biça $<$ *biçga $<$ bıç-gA; DS biçik 'kesik, biçilmiş vs.' < DS bıçık < ETü. bıçuk < bıç-(O)k). DS bıçık $\sim$ biçik

14 EDPT 1972: 294b.

15 Bk. Baskakov vd. 1968: 117 b.

16 Aydemir 2003: 123-124. 
'bucak' sözcüğü ise kanaatimizce buçgak'ın bir değişkesidir ve bıç-/biç- ile ilişkilendirilmesi söz konusu değildir (yani: DS bıçık $<* b ı c ̧ a k<$ DS bıcak $<$ bucak $<$ buçak < buçgak). DS'de biçik bıçık biçiminin 'kesik, biçilmiş; vs.' yanında 'bucak' anlamına da gelmesi, kuvvetle muhtemel buçgak'tan gelişen ve ses yapısı bakımından kendisine çok benzeyen bıçık 'bucak' biçimiyle semantik ve fonetik bir bulaşmaya (contamination) uğraması sonucu ortaya çıkmıştır (yani: biçik bıçık 'kesik, biçilmiş; vs.' bıçık 'bucak' $\rightarrow$ biçik bıçık 'bucak').

İncelediğimiz bucak sözcüğüne esas teşkil ettiğini düşündüğümüz isim biçimi -aşağıda da görüleceği üzere - bazı Türk dillerinde yalın hâlde burç $^{17}$ yahut /r/ düşmesiyle buç buc olarak yaşamaya devam etmektedir (burç $>$ buç buc). Diğer biçimlerini açıklamak için /r/ fonemini barındırıp barındırmadığını göz önünde bulundurarak üç morfolojik gelişimden bahsetmek mümkündür:

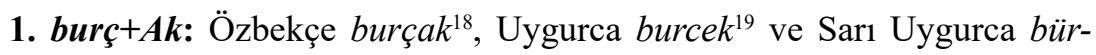
çek ${ }^{20}$ verilerini, isim köküne $+A k$ ekinin getirilmesi şeklinde çözümleyebiliriz. Türkçede çoğunlukla metaforik kullanımı olan bu ekin küçültmenin yanı sıra bir diğer fonksiyonu (kırsal) bölge özelliği gösteren isimler yapmasıdır. ${ }^{21}$ ETü. yolak $<y o l+a k(<y o l)$ 'bozkırda küçük yol, patika', boynak < boyn+ak $(<$ boyın) 'dağdaki dar geçit' ve özek< $<\ddot{z}+e k$ (< $z z$ 'vadi') 'küçük su yolu', bu eki alan sözcükler arasında zikredilebilir. ${ }^{22}$

2. * $\boldsymbol{b} \overline{\boldsymbol{u}} \boldsymbol{c}+\boldsymbol{g} \boldsymbol{A} \boldsymbol{k}$ : Türk dillerinde görece en yaygın olan biçimdir. $+g A k$ ekini "metaphorical names for body parts" başlı̆̆ 1 altında inceleyen Erdal, bu ekin organ ismi yaptığını savunur. ${ }^{23}$ Fakat Türkçedeki organ isimlerinin çoğu etimolojik bakımdan bilinmemektedir. Aydemir'e göre bu ek, bir organ yapım eki değil, Türkçede sıfat yapan ve "sözcük kökündeki şey gibi olma ya da ona karakteristik olarak benzeme” manası taşıyan bir ektir. ${ }^{24}$ Nitekim Erdal'ın DLT'de geçen ve tek

\footnotetext{
17 Bk. Kırg., Özb., Kmk.; Kazakça burış ve Kırgızca (KırgRad.) buruş verileri de burç'un yalın halde, ek almaksızın kullanımına örnek olarak gösterilebilir ; $c$ > ş sızıcılaşması ve iç ünlü türemesi (anaptyxis) sözcük bünyesinde gerçekleşen fonetik hadiselerdir (yani: burç $>*$ burş $>$ burış/buruş).

18 Bk. Borovkov 1959: $91 \mathrm{~b}$.

19 Bk. Jarring 1964: 61.

20 Bk. Malov 1957: 95.

21 Türkçede yer ismi yahut bölge özelliği gösteren isim, fiil köküne değil isim köküne $+A k$ eki getirilerek yapılır. Dolayısıyla Tietze'nin sözcüğe dair etimolojik izahı da bu bakımdan problemlidir. Bk. Erdal 1991: 40-41; krş. Tietze 2002, C. I: 387.

22 Erdal 1991: 40-41.

23 Erdal 1991: 74.

24 Detaylı bilgi için bk. Aydemir 2003: 127-129.
} 
istisna olarak kabul ettiği kidizgek kagun '(içi) keçe gibi olan kavun'25 örneğinden de ekin sıfat yaptığı anlaşılmaktadır. Fakat burada dikkat edilmesi gereken husus, nitelenen unsurun her zaman görülmemesidir ; buçgak sözcüğü de bu doğrultuda değerlendirilebilir.

Kökteki /r/ foneminin düşmesi $\left(* b u r c ̧>* b u^{r} c ̧>* b \bar{u} c ̧>b u c ̧\right)$ ve bunun sonucunda ortaya çıkan $* b \bar{u} c ̧$ biçimine $+g A k(* b \bar{u} c ̧+g a k)$ ekinin getirilmesi suretiyle oluşan, Türkçenin tarihî dönemlerinde buçgak olarak görülen bu sözcükte, bir sonraki fonetik hadise iki farklı şekilde gerçekleşir:

1. Kapantı sesi /g/'nin kök hecedeki ünlü uzunluğu dolayısıyla / $\gamma /$ üzerinden sızıcılaşması (spirantisation, fricativisation) ve kaybolması (yani: ETü.

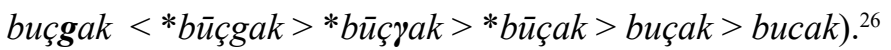

2. Kapantı sesi /g/'nin ilerleyici yarı benzeşmeyle /k/'ya dönüşerek bir yandan sertleşmesi (consonant strengthening, yani: buçgak > buçkak), diğer yandan ise bu hadisenin (başka bir dil coğrafyasında) sızıcılaşarak gırtlaksıllaşma (glottalisation) yönünde devam etmesi (yani: buçkak > buçhak $>$ buçhah).

Bu fonetik aşamalardan geçerek *būç $>b u c ̧$ kökünün müstakil kullanıldığ 1 yahut ekle genişlediği diller şu şekilde şematize edilebilir: 


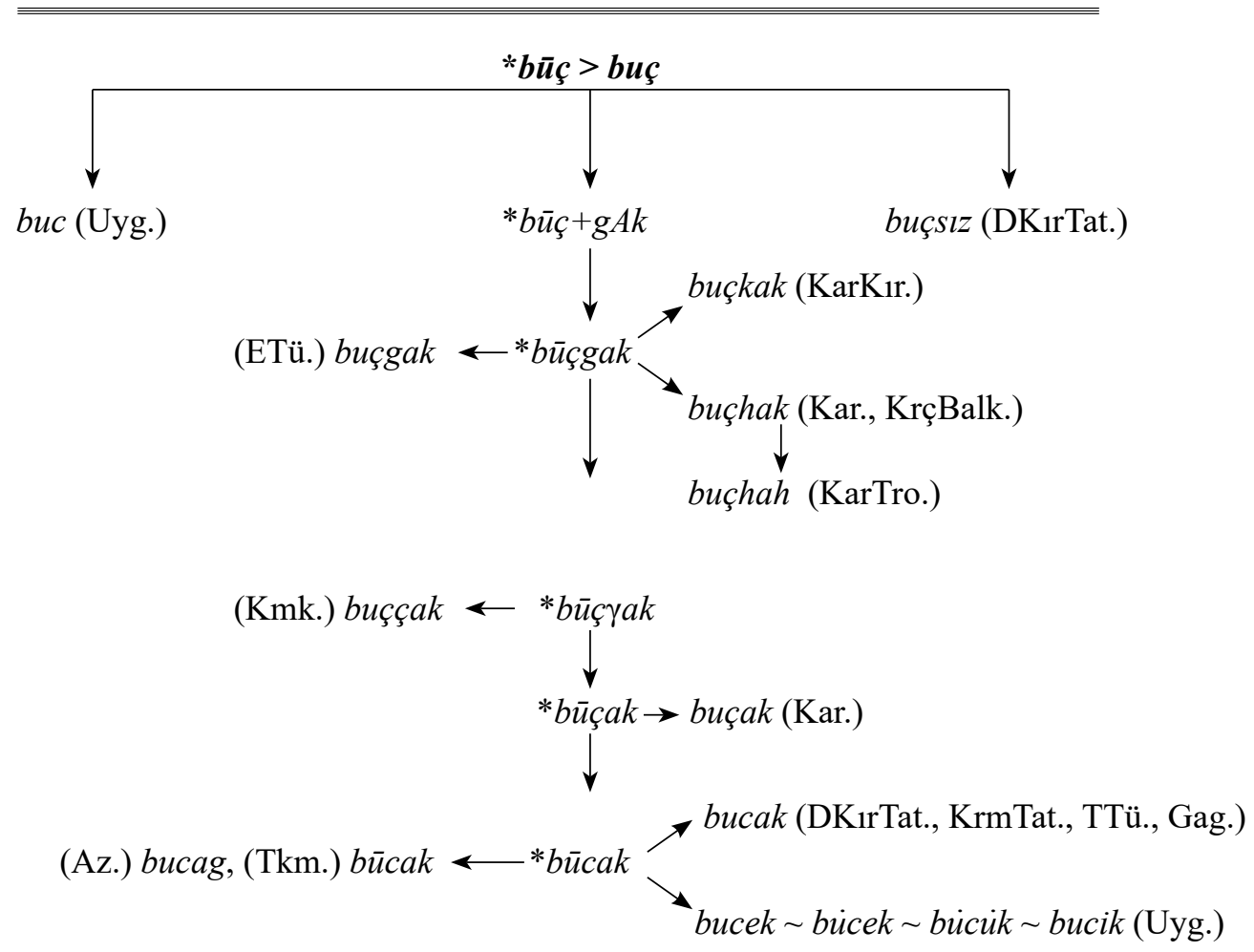

3. ${ }^{*} \boldsymbol{b} \overline{\boldsymbol{u}} c ̧+(\boldsymbol{I})-\boldsymbol{m} \boldsymbol{A} \boldsymbol{k}$ : Türkçede isme gelen bir $*+m A k$ eki olmadığından Tatarca $p o c ̧ m a k^{27}$, Çuvaşça pěśme ḩ ${ }^{28}$ ve Kazan Tatarcasındaki boçmak ${ }^{29}$ biçimlerinde, ilk aşamada $b u c ̧$ 'köşe' $(<* b \bar{u} c ̧)$ köküne, Türkçede isme gelen ve bir şeye dönüşmeyi bildiren $+I-$ ekinin $^{30}$ getirildiği ve sözcüğün böylece 'köşe haline gelmek' manası kazandığını düşünmekteyiz (yani: *būç+I- > *būçı-). Burada fiilden isim yapım eki olan $-m A k$, kanaatimizce Orta Kıpçakçada soyut isimler ve araç gereç ismi de yapan ekle ${ }^{31}$ aynı fonksiyondadır ve bu da bize Tatarca ve Kazan Tatarcasındaki biçimlerin tesadüfî olmadığını gösterir. Türkçede vurgusuz kalan orta hece ünlüsünün düşmesi hadisesinin yaygın olarak görülmesi de (bk. tokl-mak > tokımak > tokmak ${ }^{32} \mathrm{vb}$.) göz önünde bulundurulursa sözcüğün şu 
aşamalardan geçtiğini rahatlıkla söyleyebiliriz: ${ }^{*} b \bar{u} c ̧+I->* b \bar{u} c ̧ ı->* b \bar{u} c ̧ ı-m A k>$ *būçımak 'köşe haline gelme; köşe' > *būçmak > KazTat. boçmak; EBTü./Ogurca *buçmak > VBul. *puçmak ? > Tat. poçmak. Orta hece ünlüsünün düşmesine ilk hecedeki uzun $/ \bar{u} /$ da etki etmiş olabilir.

Sözcüğün Çuvaşça'daki tarihi gelişimi ise Agyagási'ye göre şu şekildedir: EBTü./Ogurca *buçmak $>$ EBTü./VBulg. *buç'mak $>$ *buç'mah $>$ *puśmah $>$ Ç. *péśmah ${ }^{33}$

\section{Sonuç}

İlk olarak Vámbéry tarafından önerilen ve çoğu araştırmacının, gelişimine dair net bir fikir sunmasa da bıç-'kesmek' fiil köküyle irtibatlandırdığı bucak sözcüğünün, Türk yazı dillerinin bazılarında burç ve buç şekillerinde yine 'köşe' manasıyla yaşamaya devam etmesi, sözcüğün semantik açıdan bıç-/biç- fiiliyle yahut Tunguzca, Korece ve Moğolca biçimlerle bir ilişkisinin olmadığını açıkça ortaya koymaktadır. Sözcügün Türk dillerindeki varyantlarını açıklamak için de isim kökünün /r/ fonemi bulundurup bulundurmaması kıstas alınarak üç morfolojik gelişim takip edilmiştir: $b u r c ̧+A k,{ }^{*} b \bar{u} c ̧+g A k,{ }^{*} b \bar{u} c ̧+I-m A k$.

Sonuç olarak bu çalışmada, araştırmacıların şimdiye kadar fiil kökünden geldiğini düşündükleri bucak sözcügünün aslında bir isim kökünden türediği, çağdaş Türk dillerindeki veriler üzerinden ortaya konmuş ve değişkeleri morfolojik açıdan temellendirilmiştir. 


\section{Kisaltmalar}

Alt. $=$ Altayca; AltGND. $=$ Gürsoy Naskali/Duranlı 1999; AltTe. $=$ Altayca'nın Teleüt ağzı; Az. = Azerbaycan Türkçesi; Bşk. = Başkurtça; BTü. $=$ Batı Türkçesi; $\mathbf{C C}=$ Grönbech 1942; Ç. = Çuvaşça; ÇağSeng. = Çağatayca Senglah; DKırTat. = Dobruca Kırım Tatarcası; DLT = Dîvânu Lugâti’t-Türk; DS = Derleme Sözlüğ̈̈; DTü. = Doğu Türkçesi; EBTü. = Eski Batı Türkçesi; EDPT = Clauson 1972; EMo. = Eski Moğolca; ETü. = Eski Türkçe; EUyg. = Eski Uygurca; Gag. = Gagauzca; H. = Halaçça; Hak. = Hakasça; HakKız. = Hakasça'nın Kızıl ağzı; Kar. = Karayca; KarCast. = Castrén 1857; KarKır. = Karayca'nın Kırım ağzı; KarTro. = Karayca'nın Troki ağzı; KazTat. = Kazan Tatarcası; KDTü. = Kuzeydoğu Türkçesi; Kırg. = Kırgızca; KırgRad. $=$ Radloff 1960; Kmk. $=$ Kumukça; KrçBalk. = Karaçay-Balkarca; KrmTat. = Kırım Tatarcası; KTü. = Kuzey Türkçesi; Kzk. = Kazakça; Mo. = Moğolca; OTü. = Orta Türkçe; Özb. = Özbekçe; $\mathbf{S}$. = Salarca; SUyg. = Sarı Uygurca; Tat. = Tatarca; Tkm. = Türkmence; Tof. $=$ Tofalarca (Karagasça); TTü. = Türkiye Türkçesi; Uyg. = Uygurca; UygJar. = Jarring 1964; VBulg. = Volga Bulgarcas1; YTü. = Yeni Türkçe. 


\section{Kaynakça}

Agyagási, K. (2019): Chuvash Historical Phonetics: An Areal Linguistic Study. With an Appendix on the Role of Proto-Mari in the History of Chuvash Vocalism. Wiesbaden.

Aydemir, H. (2003): Altaic etymologies: tōz, toprak, toyosun. Turkic Languages 7/2003: 105-143.

Bammatova, Z. Z. (1969): Kumıksko-russkiy slovar'. Moskva.

Baskakov, N. A. / Toşçakova, T. M. (1947): Oyrotsko-russkiy slovar'. Moskva.

Baskakov, N. A. / Inkijekova-Grekul, A. I. (1953): Hakassko-russkiy slovar'. Moskva.

Baskakov. N. A. / Karriyev, B. A. / Hamzayev, M. Ya. (1968): Turkmensko-russkiy slovar'. Moskva.

Baskakov, N. A. (1973): Gagauzsko-russko-moldavskiy slovar'. Moskva. (Gagauz Türkçesinin Sözlüğü. Çev. Kaynak, İ. / Doğru, A. M., Ankara, 1991).

Baskakov, N. A. / Zayonçkovskiy, A. / Şapşal, S. M. (1974): Karaimsko-russko-pol'skiy slovar'. Moskva.

Berta, Á. (1996): Deverbale Wortbildung im Mittelkiptschakisch-Türkischen, Turcologica, Band 24, Wiesbaden.

Borovkov, A. K. (1959): Uzbeksko-russkiy slovar'. Moskva.

Brockelmann, C. (1954): Osttürkische Grammatik der islamischen Litteratursprachen Mittelasiens. Leiden.

Castrén, M. A. (1857): Versuch einer koibalischen und karagassischen Sprachlehre nebst Wörterverzeichnissen aus den tatarischen Mundarten des Minussinschen Kreises. St. Petersburg.

Clauson, Sir G. (1960): Sanglax. A Persian Guide to the Turkish Language by Muhammad Mahdī Xān. Facsimile Text. London.

Clauson, Sir G. (1972): An Etymological Dictionary of Pre-Thirteenth-Century Turkish. Oxford.

Dankoff, R. / Kelly, J. (1985). Maḥmūd al-Kāšgaraì. Compendium of the Turkic Dialects (Dīwān Luүāt at-Turk). Part I. Cambridge.

DS: Türkiye'de Halk Ağzından Derleme Sözlüğü 1-12. Türk Dil Kurumu. Ankara.

Erdal, M. (1991): Old Turkic Word Formation. A Functional Approach to the Lexicon I, Wiesbaden.

Garkavets, A. N. / Üseinov, S. M. (2002): Kırımskotatarsko-russko-ukrainskiy slovar'. Sonat.

Golovkina, O. V. (1966): Tatarsko-russkiy slovar'. Moskva.

Grönbech, K. (1942): Komanisches Wörterbuch. Türkischer Wortindex zu Codex Cumanicus. Kopenhagen. 
Guseynova, G. (1941): Azerbaydjansko-russkiy slovar'. Bakü.

Gülensoy, T. (2007): Türkiye Türkçesindeki Sözcüklerin Köken Bilgisi Sözlüğ̈̈. Ankara.

Gürsoy-Naskali, E. / Duranlı, M. (1999): Altayca-Türkçe Sözlük. Ankara.

Fedotov, M. R. (1996): Etimologiçeskiy slovar' çuvaşskogo yazıka. Tom I. Çeboksarı.

Jarring, G. (1964): An Eastern Turki-English Dialect Dictionary. Lund.

Joki, A. J. (1953): Wörterverzeichnis der Kyzyl-Sprache. Studia Orientalia, 19/1953:1-47.

Karahan, S. O. (2011): Dobruca Kırımtatar Ağzı Sözlüğü. Dictionarul Graiului Tătar Dobrogean 1, $A-D$. Romanya.

Karatay, O. (2014): Karadeniz Kuzeyindeki Bucak Yeradının Kökenine Dair. Karadeniz Araştırmaları, S. 43, Güz 2014, 51-57.

Kzk.: Türk Dil Kurumu (Karşılaşstırmalı Türk Lehçeleri Sözlüğ̈̈) https://sozluk.gov.tr (Erişim tarihi: 17.05.2020)

Malov, S. E. (1957): Yazık jeltıh uygurov. Slovar'i grammatika. Alma-Ata.

Nadjip, Ė. N. (1968): Uygursko-russkiy slovar'. Moskva.

Nişanyan, S. (2009): Sözlerin Soyă̆acı. Çağdaş Türkçenin Etimoloji Sözlü̆̆̈̈. İstanbul.

Oda, J. (2015): A Study of the Buddhist Sūtra called Sekiz Yükmek Yaruk or Sekiz Törlügin Yarumış Yaltrımış in Old Turkic. Belgium.

Radloff, W. (1960): Versuch eines Wörterbuches der Türk-dialecte (Opıt'slovarya tyurkskih' nareçıy). Band IV. Gravenhage.

Ramstedt, G. J. (1935): Kalmukisches Wörterbuch. Helsinki.

Rassadin. V. I. (2005): Slovar'Tofalarsko-russkiy i Russko-tofalarskiy. Sankt-Peterburg.

Räsänen, M. (1969): Versuch eines etymologischen Wörterbuchs der Türksprachen. Helsinki.

Ryumina-Sırkaşeva, L. T. / Kuçigaşeva, N. A. (1995): Teleutsko-russkiy slovar'. Kemerovo ( Teleüt Ağzı Sözlüğü. Çev. Akalın, Ş. H. / Turgunbayev, C., Ankara, 2000)

Sevortyan, E. V. (1978): Etimologiçeskiy Slovar'Tyurskih Yazıkov II, Moskva.

Starostin, S. / Dybo, A. / Mudrak, O. (with assistance of İlya Gruntov and Vladimir Glumov) (2003): An Etymological Dictionary of the Altaic Languages. (Handbook of Oriental Studies: Uralic \& Central Asian Studies, Vol. 8/1-3). Leiden-Boston.

Tavkul, U. (2000): Karaçay-Malkar Türkçesi Sözlüğü. Ankara.

Tietze, A. (2002): Tarihi ve Etimolojik Türkiye Türkçesi Lugatt. Sprachgeschichtliches und etymologisches Wörterbuch des Türkei-Türkischen 1, A-E. İstanbul- Wien.

Vámbéry H. (1878): Etymologisches Wörterbuch der Turko-Tatarischen Sprachen. Leipzig.

Yudahin, K. K. (1965): Kirgizsko-russkiy slovar'. Moskva. 